\title{
OPTIMIZATION OF AZ91D MAGNESIUM ALLOY FRICTION STIR WELDED JOINTS BY TAGUCHI METHOD
}

\author{
K. RAJESH KUMAR ${ }^{1}$, KIRAN KUMAR DAMA ${ }^{2} \&$ V. V. SATYANARAYANA ${ }^{3}$ \\ ${ }^{1}$ Scholar, Department of Mechanical Engineering, Koneru Lakshmaiah Educational Foundation, \\ Vaddeshwaram, Andhra Pradesh, India \\ ${ }^{2}$ Associate Professor, Department of Mechanical Engineering, Koneru Lakshmaiah Educational Foundation, \\ Vaddeshwaram, Andhra Pradesh, India \\ ${ }^{3}$ Professor, Department of Mechanical Engineering, Vidya Jyothi Institute of Technology, Hyderabad, India
}

\begin{abstract}
Friction stir welding (FSW) of AZ 91D Magnesium alloy has been undertaken with an objective to find the optimal parameter condition for the mechanical properties of the welded joints. Empirical regression equations are developed for all the responses. The variation in mechanical properties at different parameter combination is attributed to change in microstructure during the welding process. Tool tilt angle is governing uttermost while a comprehensive study on all mechanical properties is concerned.

KEY WORDS: FSW, Magnesium Alloy AZ 91D, UTS, Impact Toughness \& Micro Hardness
\end{abstract}

Received: Jan 16, 2020; Accepted: Feb 06, 2020; Published: Mar 14, 2020; Paper Id.: IJMPERDAPR202052

\section{INTRODUCTION}

Magnesium alloys are increasingly employed in automotive industry owing to their low density and high stiffness to weight ratio [1]. Fusion welding processes are scarcely used to fabricate these alloys due to their low melting point and high susceptibility to hot crack formation. Friction stir welding process among the solid state welding processes is a prospective method employed to join these alloys effectively and eliminating the formation of weld defects. The friction stir joints of AZ91D magnesium alloy at high speeds resulted in fine grain microstructure with improved mechanical properties [2]. The tensile properties of the AZ31B magnesium alloy friction stir weld joints are superior compared to other welding processes [3]. Apart from the usual, FSW parameters including the parameter axial force were also implemented and mechanical strength of the joint was investigated [4]. Welding of AZ61A magnesium alloy by FSW was investigated and empirical models of response have been developed employing response surface methodology [5]. The tool geometry has played major role in generating the heat and material dispersion which consequently affected the mechanical and metallurgical properties of friction welded aluminum alloy joints [6,7]. The tool geometry in the friction stir welding of AZ31B magnesium alloy has governed major role by changing the microstructure and consequently the mechanical properties [8].

In this investigation effect of process parameters on AZ91D magnesium alloy is conducted in order to have a comprehensive optimal output of the mechanical properties of the joints. 


\section{EXPERIMENTAL DETAILS}

\section{Materials}

The material used in this study was AZ91D magnesium alloy manufactured through die casting process. The chemical composition and mechanical properties of the material are given in table 1 and table 2 respectively.

Table 1: Chemical Composition of AZ91D Magnesium Alloy

\begin{tabular}{|c|c|c|c|c|c|c|c|c|}
\hline \multirow{2}{*}{ Material } & \multicolumn{7}{|c|}{ Element \% in Weight } \\
\cline { 2 - 9 } & $\mathbf{M g}$ & $\mathbf{A l}$ & $\mathbf{Z n}$ & $\mathbf{S i}$ & $\mathbf{M n}$ & $\mathbf{C u}$ & $\mathbf{F e}$ & $\mathbf{O}$ \\
\hline AZ91D & 90.2 & 8.7 & 0.95 & 0.035 & 0.05 & 0.003 & 0.01 & 0.05 \\
\hline
\end{tabular}

Table 2: Mechanical \& Thermal Properties of AZ91D Magnesium Alloy

\begin{tabular}{|c|c|c|c|c|c|}
\hline Material & UTS (M Pa) & Yield Strength (M Pa) & \% Elongation & $\begin{array}{c}\text { Thermal } \\
\text { Conductivity } \\
\left(\mathbf{W} / \mathbf{m}^{\circ} \mathbf{K}\right)\end{array}$ & $\begin{array}{c}\text { Melting } \\
\left.\text { Temperature ( }{ }^{\circ} \mathbf{C}\right)\end{array}$ \\
\hline AZ91D & 230 & 160 & 3 & 72 & 533 \\
\hline
\end{tabular}

The materials are available in the form of plates of $5 \mathrm{~mm}$ thick and machined to a size of $100 \mathrm{mmX} 100 \mathrm{~mm}$ for metal joining.

\section{Friction Welding Process}

A non consumable rotating tool with a specially designed geometry inserted at the interface of the plates to be joined and transverses further. Due to friction, heat is generated and causes the plastic deformation of the metal. The tool shoulder consolidates the material and helps in making a sound joint [9]. The FSW process was carried out on a vertical milling machine as shown in figure $1 \mathrm{a}$. The tool employed for the welding process was shown in figure $1 \mathrm{~b}$

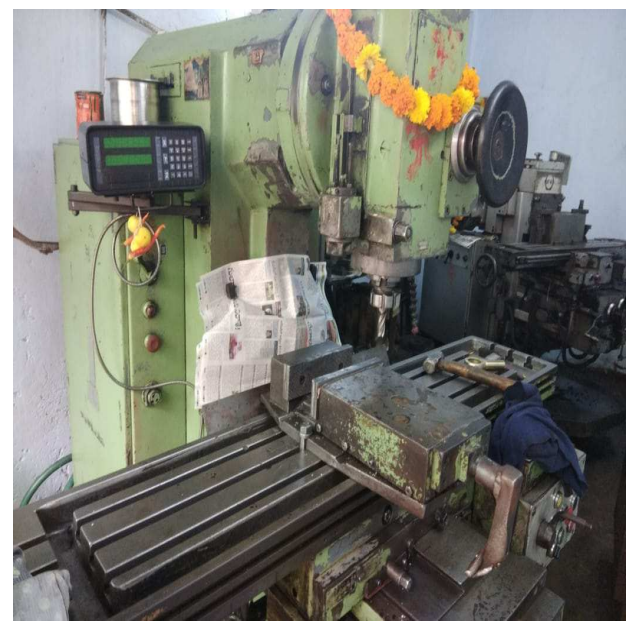

(a) Vertical Milling Machine.

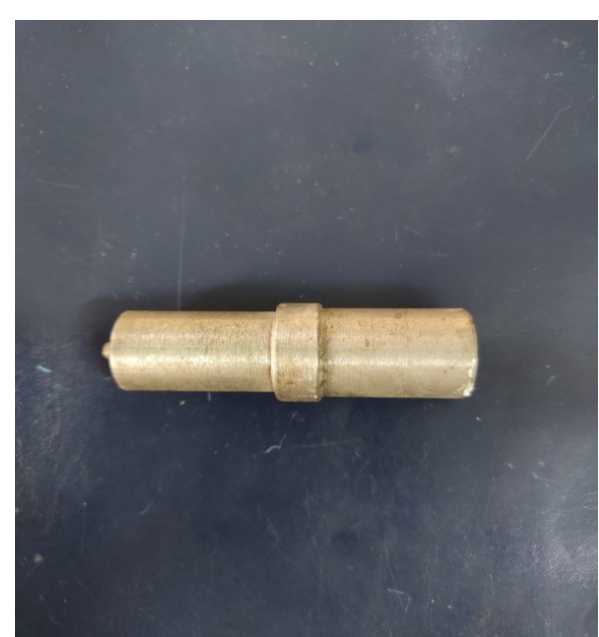

(b) FSW Process Tool.

Figure 1: Friction Welding Machine and the Tool.

It has a provision to change the rotational speed, travelling weld speed and angular position of the tool. The parameters employed and the range of each one is given in the table 3 . 
Table 3: FSW Process Parameters

\begin{tabular}{|l|c|c|c|c|}
\hline \multirow{2}{*}{\multicolumn{1}{c|}{ Parameters }} & \multirow{2}{*}{ Units } & \multicolumn{3}{|c|}{ Levels } \\
\cline { 3 - 5 } & & Low & Medium & High \\
\hline Rotational Speed $\left(\mathrm{X}_{1}\right)$ & r.p.m & 710 & 900 & 1100 \\
\hline Weld speed $\left(\mathrm{X}_{2}\right)$ & $\mathrm{mm} / \mathrm{min}$. & 16 & 20 & 25 \\
\hline Tool tilt Angle $\left(\mathrm{X}_{3}\right)$ & 0 & 2 & 2.5 & 3 \\
\hline
\end{tabular}

\section{MECHANICAL AND METALLURGICAL PROPERTY EVALUATION}

\section{Tensile Test}

The tensile test was performed on a Universal Testing Machine (figure2) at a cross head speed of $0.5 \mathrm{~mm} / \mathrm{minute}$.

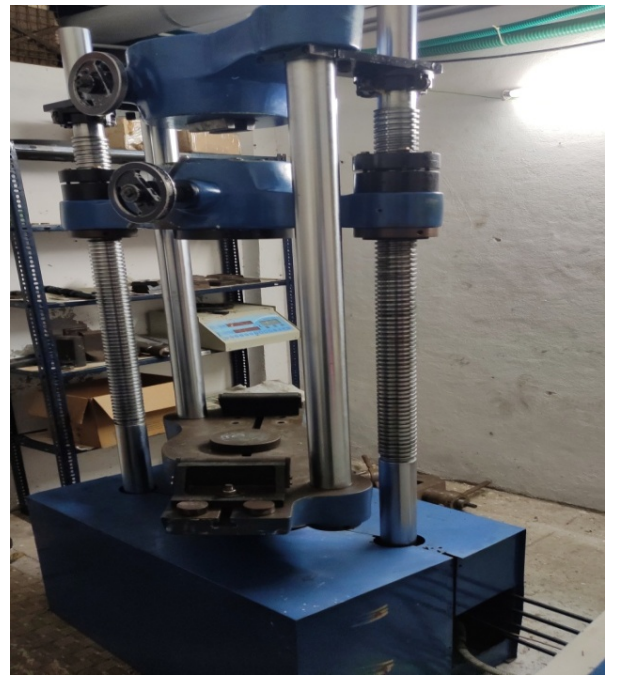

Figure 2: Universal Testing Machine.

The specimen is fabricated as per ASTM E08 standard (figure 3a \& figure 3b) and is employed for evaluation of ultimate tensile strength of the joints.

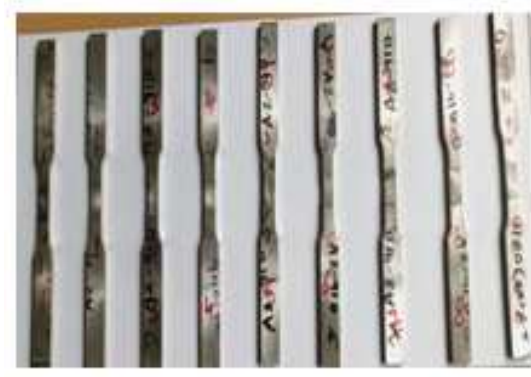

Figure 3.a Welded Tensile specimen samples ASTME08

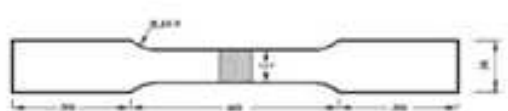

Figure 3.b Tensile specimen samples as per ASTME08

Figure 3: Tensile Specimen.

\section{Impact Test}

The Charpy Impact test (figure.4) was carried out at room temperature and the specimen were sectioned from the weldment with specimen axis transverse to the weld joint with notch location at the weld centre. 


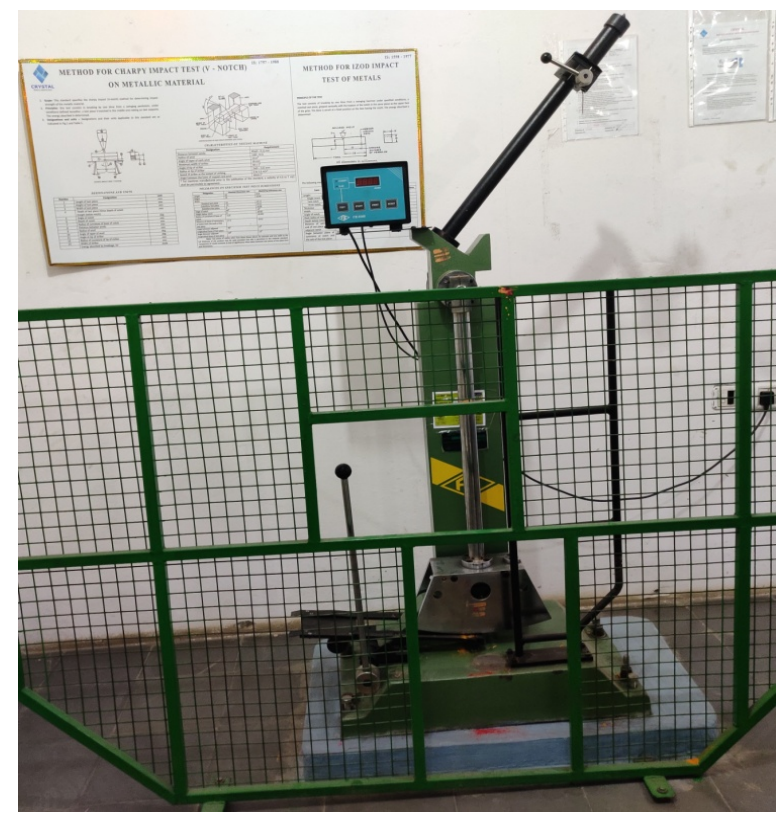

Figure 4: Charpy Impact Test Machine.

The specimen is made as per ASTM E23 standard as shown in (figure.5).
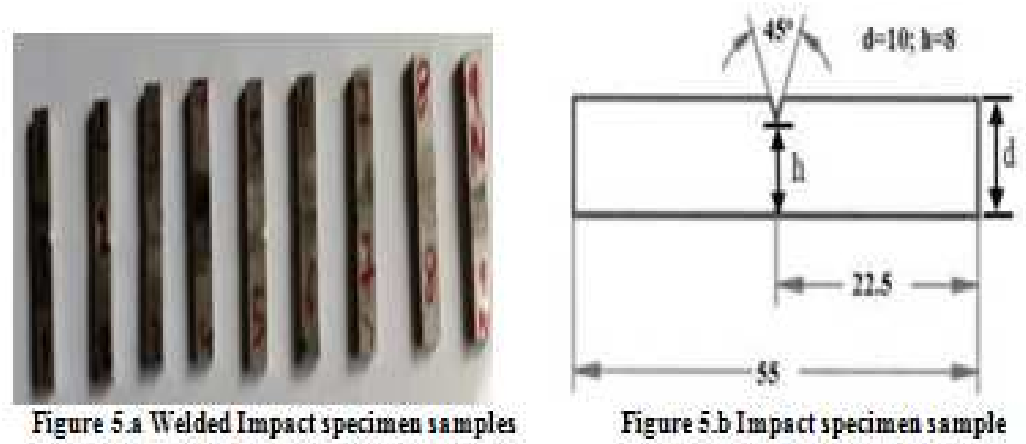

Figure 5: Impact Specimens.

\section{Hardness}

Micro hardness test was carried out using Olympus digital micro hardness tester at a load of 100 gram. The hardness machine employed for the evaluation is shown in (figure.6). The hardness of the welded joint is measured at an interval of $0.5 \mathrm{~mm}$.

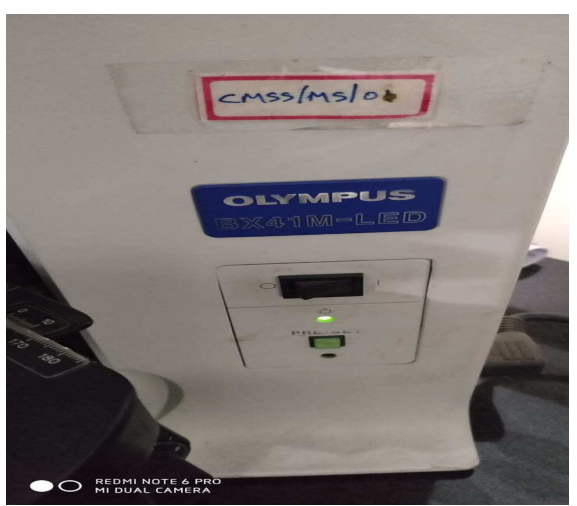

Figure 6: Olympus Micro Hardness Tester. 


\section{Metallography}

Olympus optical microscope was used for examining the microstructure of welded joints (figure7). The base metal and the welded joint microstructure are captured for analysis.

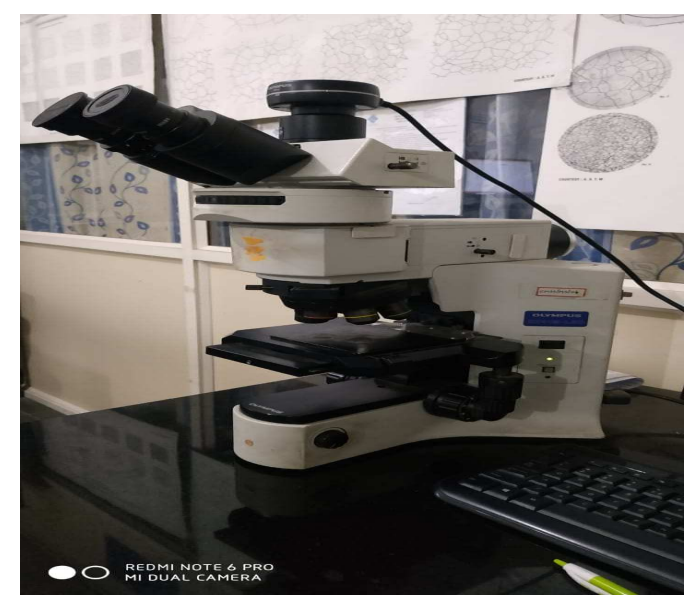

Figure 7: Olympus Optical Microscope.

\section{Taguchi Analysis}

In this investigation, three process parameters at three levels each have been taken and design of experiments is conducted as per L9 Taghuchi array [10,11], which is shown in table 4 . .

Table 4: L9 Orthogonal Array

\begin{tabular}{|c|c|c|c|}
\hline Run & $\begin{array}{c}\text { Speed(rpm } \\
(\mathbf{X 1})\end{array}$ & $\begin{array}{c}\text { Feed (mm/min) } \\
(\mathbf{X} 2)\end{array}$ & $\begin{array}{c}\left.\text { Angle( } \mathbf{(}^{\mathbf{}}\right) \\
(\mathbf{X} 3)\end{array}$ \\
\hline 1 & 710 & 16 & 2 \\
\hline 2 & 710 & 20 & 2.5 \\
\hline 3 & 710 & 25 & 3 \\
\hline 4 & 900 & 16 & 2.5 \\
\hline 5 & 900 & 20 & 3 \\
\hline 6 & 900 & 25 & 2 \\
\hline 7 & 1100 & 16 & 3 \\
\hline 8 & 1100 & 20 & 2 \\
\hline 9 & 1100 & 25 & 2.5 \\
\hline
\end{tabular}

\section{Regression Analysis}

The data have been subjected to regression analysis and the response regression equations are developed. The Analysis Of Variance (ANOVA) is conducted using Yate's algorithm [12]. The regression equation for the response (y) is developed in the coded values of the parameters that is undertaken in the investigation:

$$
\mathrm{Y}=\mathrm{b}_{0}+\mathrm{b}_{1} \mathrm{x}_{1}+\mathrm{b}_{2} \mathrm{x}_{2}+\mathrm{b}_{3} \mathrm{x}_{3}+\mathrm{b}_{4} \mathrm{x}_{1} \mathrm{x}_{2}+\mathrm{b}_{5} \mathrm{x}_{1} \mathrm{x}_{3}+\mathrm{b}_{6} \mathrm{x}_{2} \mathrm{x}_{3}
$$

\section{RESULTS AND ANALYSIS}

The experimentation has been carried out as per Taguchi array and performed randomly with a view to reduce bias and error. The results have been compiled in Table5. 
Table 5: Mechanical Properties of AZ91D Magnesium alloy FSW Joints

\begin{tabular}{|c|c|c|c|c|c|c|}
\hline \multirow{2}{*}{ Run } & \multicolumn{2}{|c|}{ UTS (MPa) } & \multicolumn{2}{c|}{ Impact Toughness (Joules) } & \multicolumn{2}{c|}{ Hardness } \\
\cline { 2 - 7 } & Trial1 & Trial2 & Trial1 & Trial2 & Trial1 & Trial2 \\
\hline 1 & 102 & 100.45 & 1.25 & 1 & 84.31 & 85.74 \\
\hline 2 & 32 & 31.3 & 2.75 & 2.5 & 90 & 91 \\
\hline 3 & 115 & 113.96 & 1.25 & 1 & 114 & 118 \\
\hline 4 & 113 & 110 & 2.25 & 2 & 90 & 91 \\
\hline 5 & 66 & 67.06 & 1.25 & 1.5 & 91 & 93 \\
\hline 6 & 67 & 67.06 & 0.75 & 0.5 & 90 & 91 \\
\hline 7 & 115 & 114.04 & 1.75 & 1.5 & 103 & 104 \\
\hline 8 & 80 & 81.93 & 0.75 & 0.5 & 96 & 95 \\
\hline 9 & 103 & 104.53 & 1.75 & 1.5 & 90 & 89 \\
\hline
\end{tabular}

The data have been analyzed and ANOVA is conducted for all the responses. The regression equations for the responses are shown in Table.6.

Table 6: Regression Equation

\begin{tabular}{|c|c|c|c|}
\hline S. No. & Property & $\begin{array}{l}\text { Regression } \\
\text { Equation }\end{array}$ & $\begin{array}{l}\text { Coefficient of } \\
\text { Correlation }\end{array}$ \\
\hline 1 & UTS & $\begin{array}{c}\mathrm{Y}=87.963+ \\
5.766 \mathrm{X}_{1^{-}} \\
4.663 \mathrm{X}_{2}+5 \\
146 \mathrm{X}_{3^{-}} \\
.668 \mathrm{X}_{1} \mathrm{X}_{2}+ \\
2.256 \mathrm{X}_{1} \mathrm{X}_{3} \\
+3.795 \mathrm{X}_{2} \mathrm{X} \\
3\end{array}$ & 0.7 \\
\hline 2 & $\begin{array}{l}\text { Impact } \\
\text { Toughne } \\
\text { ss }\end{array}$ & $\begin{array}{c}\mathrm{Y}=1.4311- \\
0.0111 \mathrm{X}_{1^{-}} \\
0.167 \mathrm{X}_{2}+0 \\
194 \mathrm{X}_{3}+0.1 \\
11 \mathrm{X}_{1} \mathrm{X}_{3}\end{array}$ & 0.72 \\
\hline 3 & Hardness & $\begin{array}{c}\mathrm{Y}=94.781- \\
0.336 \mathrm{X}_{1}+1 \\
886 \mathrm{X}_{2}+4.4 \\
97 \mathrm{X}_{3}- \\
4.497 \mathrm{X}_{1} \mathrm{X}_{2-} \\
2.553 \mathrm{X}_{1} \mathrm{X}_{3} \\
+0.781 \mathrm{X}_{2} \mathrm{X} \\
3 \\
\end{array}$ & 0.65 \\
\hline
\end{tabular}

A typical ANOVA table for UTS is given in table7.

Table 7: ANOVA for UTS of the Weld Joint

\begin{tabular}{|c|c|c|c|c|c|}
\hline Coef & Est & SS & DOF & MS & F \\
\hline b0 & 87.963 & - & - & - & \\
\hline b1 & 5.766 & 598.465 & 2 & 299.232 & 0.135075081 \\
\hline b2 & -4.663 & 391.440 & 2 & 195.720 & 0.088349103 \\
\hline b3 & 5.146 & 476.581 & 2 & 238.291 & 0.10756569 \\
\hline b4 & -2.668 & 128.107 & 2 & 64.053 & 0.028914023 \\
\hline b5 & 2.256 & 91.576 & 2 & 45.788 & 0.020668848 \\
\hline b6 & 3.795 & 259.236 & 2 & 129.618 & 0.058510362 \\
\hline SSR & & 1945.405 & 12 & & \\
\hline SSE & & 11076.519 & 5 & 2215.304 & \\
\hline SST & & 13021.924 & 17 & & \\
\hline
\end{tabular}


The data given in table 5 is written in the form of Taghuchi $\mathrm{S} / \mathrm{N}$ Equations:

Table 8: S/N Equations

\begin{tabular}{|c|c|}
\hline \multicolumn{1}{|c|}{ Criterion } & S/N Equation \\
\hline Higher the Better & $-10 \log \left[1 / \mathrm{n} \Sigma 1 / \mathrm{y}_{\mathrm{i}}{ }^{2}\right]$ \\
\hline Lower the Better & $-10 \log \left[1 / \mathrm{n} \Sigma \mathrm{y}_{\mathrm{i}}{ }^{2}\right]$ \\
\hline
\end{tabular}

Higher the better criterion is applied to strength and impact toughness while lower the better is applied to hardness, as shown in Table8. The average of the $\mathrm{S} / \mathrm{N}$ values of the responses is given in the table 9 . The modified Taguchi analysis is conducted by taking the average of all $\mathrm{S} / \mathrm{N}$ values of the responses into consideration [11].

Table 9: S/N Values of Responses

\begin{tabular}{|c|c|}
\hline Run & $\begin{array}{c}\text { Average } \\
\text { S/N }\end{array}$ \\
\hline 1 & 0.169046 \\
\hline 2 & -0.13502 \\
\hline 3 & -0.00034 \\
\hline 4 & 0.862623 \\
\hline 5 & 0.096696 \\
\hline 6 & -0.95291 \\
\hline 7 & 0.489581 \\
\hline 8 & -0.82191 \\
\hline 9 & 0.535755 \\
\hline
\end{tabular}

\section{DISCUSSIONS}

The tensile strength was highest when rotational speed was at the lowest level while the other two parameters were at their highest levels. To the contrary, the strength was lowest and impact toughness was highest when the rotational speed was lowest while weld speed and tool tilt angle were at their mid level. When the rotational speed was high resulting in high heat input and slower cooling rate causes excessive grain growth (figure8) and subsequently gives rises lower tensile strength and high impact strength [5]. The lowest hardness of the joint was obtained when all the parameters were at their lowest level. A typical hardness survey shows that the hardness was high at weld centre. It has reduced while travelling towards base metal (figure9).

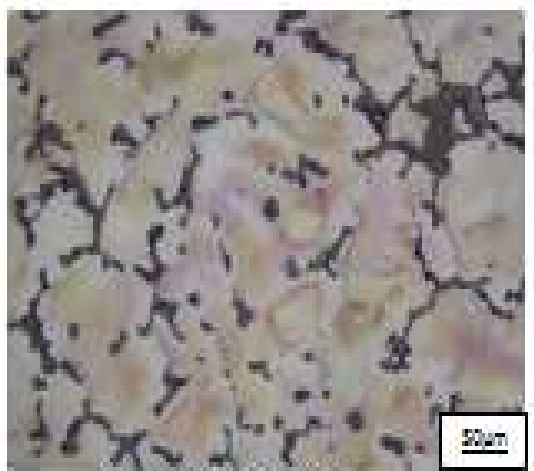

Figuresi Bne Mttal

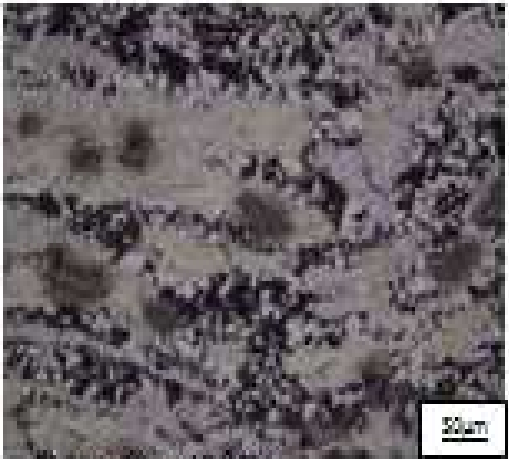

Figuesb Weld Znot

Figure 8: Microstructure of AZ 91D Base Metal and Weld Zone.

It is attributed to the difference in grain size at different zones in (figure9). 


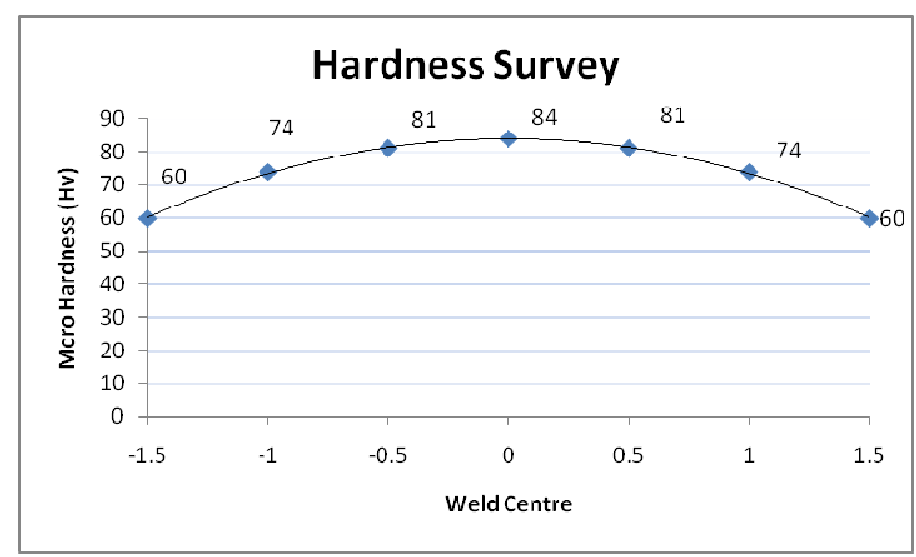

Figure 9: Hardness Survey.

The regression equations developed shall be employed for estimating the responses at different input parameter values. The coefficient of correlation indicates a good relationship between parameters and the responses. The S/N data was subjected to analysis of means Table10 indicating that the tool tilt angle is playing the major role while weld speed and tool rotational speed governs the responses in the descending order respectively.

Table 10: Analysis of Means

\begin{tabular}{|c|c|c|c|c|c|}
\hline Parameter & L1 & L2 & L3 & Range & Rank \\
\hline $\mathbf{X}_{\mathbf{1}}$ & 0.01123 & 0.002137 & 0.067809 & 0.065672621 & 3 \\
\hline $\mathbf{X}_{\mathbf{2}}$ & 0.507083 & -0.28674 & 0.195313 & 0.793826139 & 2 \\
\hline $\mathbf{X}_{\mathbf{3}}$ & -0.53526 & 0.42112 & 0.195313 & 0.95637636 & 1 \\
\hline
\end{tabular}

The optimal parameter conditions were given in table 11. The weld speed should be low while the tool tilt angle should be kept at the mid level for having all the responses at optimal conditions. The tool tilt caused the vortex flow occurred in lower half of the work piece for the stir zone resulting in dynamic recrystalization predicted optimal value is found from the equation: $\mathbf{m}+\boldsymbol{\Sigma} \mathbf{d}_{\mathbf{i}}$; where $\mathrm{m}$ is grand mean and $\mathrm{d}_{\mathrm{i}}$ is the deviation of the larger $\mathrm{S} / \mathrm{N}$ value from the grand mean.

Table 11: Optimal Parameter Conditions

\begin{tabular}{|l|c|c|}
\hline \multicolumn{1}{|c|}{ Parameters } & Notations & Level of Parameters \\
\hline Rotational Speed & $X_{1}$ & L3 \\
\hline Weld Speed & $X_{2}$ & L1 \\
\hline Tilt Angle & $X_{3}$ & L2 \\
\hline
\end{tabular}

A confirmation experiment is conducted and the responses obtained are given in table 12 .

Table 12: Optimal Responses

\begin{tabular}{|c|c|c|}
\hline UTS (MPa) & Impact Toughness (Joules) & Hardness (Hv) \\
\hline 99 & 1.75 & 80 \\
\hline
\end{tabular}

\section{CONCLUSIONS}

- Empirical model for responses have been developed with moderate degree of coefficient of correlation between the responses and parameters and can be effectively used to predict the responses with $90 \%$ confidence level.

- Tool tilt causes vortex flow in the stir zone and recrystalization has occurred resulting in variation of mechanical properties. 


\section{ACKNOWLEDGEMENTS}

The authors thank the management of Koneru Laksmaiah Educational Foundation and Vidya Jyothi Institute of Technology for the support extended during this work.

\section{REFERENCES}

1. Singh Kulwant, Review on Friction stir welding of Magnesium alloys, Journal of magnesium alloys, 2018 Vol.-6, Issue No.4, pp 399-416

2. Won-Bae Lee, Jong Woong Kim, Yun-Mo Yeon and Senug-Boo Jung, The joint characteristics of friction of friction stir welded AZ91D magnesium alloy, Material Transaction, 2013, Vol.-44. Issue No.5, pp.917-923

3. Padmanaban G. and Balsubramanian V., An experimental investigation on friction stir welding of AZ31B magnesium alloy, International Journal of Advanced Manufacturing and Technology.2010, Vol.-49. Issue 1-4, pp.111-121

4. R. Senthilraja and A. Naveen Sait, Optimisation offriction stir welding parameters for magnesium alloy AZ91D using Taghuchi Design, Physicochemcal Mechanics of Materials,2015, Vol.-02, pp. 36-41

5. Chu, NGOC-HUNG, and V. D. Nguyen. "The Multi-Response Optimization of Machining Parameters in the Ultrasonic Assisted Deep-Hole Drilling Using Grey-Based Taguchi Method." Int. J. Mech. Prod. Eng. Res. Dev 8 (2018): 417-426.

6. S. Rajkumar, A. Razalrose, V. Balasubramanian, "Friction stir welding of AZ61A magnesium alloy", International Journal of Advanced Manufacturing Technology, 2013, Vol.-68, pp. 277-292,

7. Elangovan K. and Balasubramanian V. Influences of pin profile and rotational speed of the tool and formation of friction stir processing zone in AA2219 aluminum alloy, Material Science And Engineering.-,2007, A 459. pp.7-18,

8. Ugender Singrapre, Kumar Adepu, Somireddy Arumalle, “ Influence of tool material and rotational speed on mechanical properties of friction stir welded AZ31B magnesium alloy”, Journal of Magnesium alloys 2015, Vol.-3, pp.335-344,

9. Alavala, Chennakesava R. "Effect of Temperature, Strain Rate and Coefficient of Friction on Deep Drawing Process of 6061 Aluminum Alloy." International Journal of Mechanical Engineering 5.6 (2016): 11-24.

10. Phillip J. Ross, Taguchi Techniques for Quality Engineering, McGraw-Hill Professional, 1995,2nd edition

11. J. Jagadesh Kumar, G. Diwakar, Vaddi Venkata Satyanarayana, Impact of High-Velocity Oxy-Fuel ZrO $\mathrm{Z}_{2} \mathrm{Coating}_{\mathrm{s}}$ on Corrosion Resistance and Fatigue Life of AISI 316L Austenitic Stainless Steel, Advances in Materials Science and Engineering, 2019, Vol.-2019, Article ID 5719694, https://doi.org/10.1155/2019/5719694,.

12. Alsoufi, Mohammad S., and Mohammed Yunus. "Effect of Heat Treatment on Stress Corrosion Cracking Resistance of AL-ZNMG-CU Alloy used in Aerospace Engineering Applications."

13. Kempthorne, Design and analysis of experiments, John Wiley and sons, Newyork.-1987, Vol.-2 


\section{AUTHORS PROFILE}

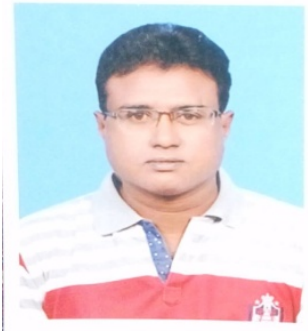

K. Rajesh Kumar is a research Scholar, pursuing Ph.D. from Koneru Laksmaiah University, Vijayawada. Completed his Master's of Engineering in Production Engineering from Biju Patnaik Technological, University. Is currently working as an Associate Professor in Department of Mechanical Engineering in Vidya Jyothi Institute of Technology, Hyderabad, Telengana State. He had published 4 technical papers reviewed international journals and applied for one patents with Indian Patent office.

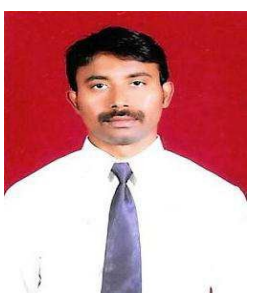

Dr. Kiran Kumar Dama is a Mechanical Engineer, having Master's and Doctoral Degrees from NIT W and has over 9 years of professional experience, which includes 7 years (pre-Ph.D) as a Sr. Software Engineer, Sr. Design Engineer, CAE Engineer/Analyst, and 2 years (post-Ph.D.) as an Associate Professor of Mechanical Engineering Department, Koneru Lakshmaiah Education Foundation (KLEF) Green Fields, Vaddeswaram, Andhra Pradesh, INDIA. He was a speaker in One-Week GIAN course at NITW, and has publications of 15 SCOPUS papers, 8 International Conference Proceedings, and 1National Conference Proceedings from 2015 to 2020.

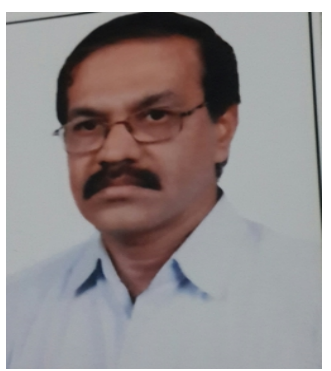

Dr V. V. Satyanarayana did his PhD from JNTU Hyderabad, India in Mechanical Engineering with a specific domain of welding engineering. He had published 34 technical papers reviewed international and national journals and applied for two patents with Indian Patent office; Also he presented 18 papers at International and national conferences. His areas of research include manufacturing, alternate fuels and reverse engineering. He is a Fellow of Institution of Engineer and life member of Indian Institute of Welding. 